\title{
ANALISIS DAMPAK EKONOMI DAN LINGKUNGAN KEGIATAN WISATA DI PANTAI SUWUK KEBUMEN
}

\author{
Indah Rohyani ${ }^{1}$ Siti Nur Azizah ${ }^{2}$ \\ STIE Putra Bangsa \\ Abstrak
}

Tujuan penelitan ini adalah untuk mengidentifikasi dampak ekonomi dengan metode deskriptive kuantitatif berdasarkan karakteristik pengunjung, tenaga kerja dan pelaku usaha wisata pantai Suwuk serta dampak lingkungan yang ditimbulkannya. Pariwisata di Pantai Suwuk dinilai memberikan kontribusi yang baik karena mampu menyerap tenaga kerja dan meningkatkan usaha di wilayah tersebut. Dampak terhadap lingkungan dari adanya kegiatan wisata di objek wisata Pantai Suwuk menurut persepsi responden wisatawan, pemilik unit usaha, dan tenaga kerja dinilai kurang baik dalam hal pengelolaan sampah namun dampak lingkungan untuk kondisi perairan laut, kondisi udara, dan keindahan alam (Panorama), sebagian besar responden memberikan penilaian yang positif

Kata kunci: Pantai Suwuk, dampak ekonomi, dampak lingkungan

\section{A. Pendahuluan}

\subsection{Latar Belakang}

Kabupaten Kebumen memiliki banyak potensi wisata alam diantarnya pantai sepanjang pesisir laut selatan dan merupakan sumber pendapatan daerah. Salah satu potensi sumberdaya di kawasan pesisir yang dapat dijadikan obyeki wisata adalah Pantai Suwuk menjadi destinasi wisata yang cukup diminati.

Pantai ini menjadi salah satu andalan pemasukan dari wisata yang ada di Kebumen. Minat masyarakat cukup tinggi dilihat dari angka kunjungan ke pantai ini, berdasarkan data BPS 2018 angka kunjungan 287.085 orang Hal ini menimbulkan dapat dampak positif terhadap ekonomi masyarakat. Penelitian ini mengunakan pengukuran deskriptive pada kegiatan ekonomi di pantai Suwuk. Selain itu penelitian ini akan mengidentifikasi karakteristik pengunjung, unit usaha, dan tenaga kerja wisata Pantai Suwuk serta mengetahui persepsi dampak lingkungan yang timbul karena adanya kegiatan wisata seperti sampah, perairan dan kualitas udara.

\subsection{Masalah Penelitian}

1. Apakah dampak ekonomi objek wisata Pantai Suwuk?

2. Bagaimana dampak lingkungan dari adanya kegiatan wisata di objek wisata Pantai Suwuk?

\subsection{Tujuan penelitian}

Tujuan penelitan ini adalah untuk mengidentifikasi karakteristik pengunjung, tenaga kerja dan pelaku usaha wisata pantai Suwuk serta dampak lingkungan yang 
ditimbulkannya Informasi ini diharapkan dapat menjadi bahan pertimbangan dan membantu pengambilan keputusan bagi pihakpihak terkait, khususnya pemerintah Kebumenl dalam menentukan kebijakan pengembangan iwisata Pantai Suwuk dan melakukan perbaikan sarana dan prasarana wisata dalam rangka meningkatkan kesejahteraan masyarakat sekitar.

\section{B. Kajian Pustaka}

Pengembangan tempat wisata memiliki dampak dampak terhadap lingkungan sekitarnya. Gee (1989) mengatakan adanya dampak atau pengaruh yang positif maupun negatifkarena adanya pengembangan pariwisata dan kunjungan wisatawan yang meningkat berupa lingkungan, ekonomi dan sosial.

Masyarakat dalam lingkungan suatu obyek wisata sangatlah penting dalam kehidupan suatu obyek wisata karena mereka memiliki kultur yang dapat menjadi daya tarik wisata, dukungan masyarakat terhadap tempat wisata berupa sarana kebutuhan pokok untuk tempat obyek wisata, tenaga kerja yang memadai dimana pihak pengelola obyek wisata memerlukannya untuk menunjang keberlangsungan hidup obyek wisata dan memuaskan masyarakat yang memerlukan pekerjaan dimana membuat kehidupan masyarakat menjadi lebih baik.Pengembangan suatu obyek wisata yang dilakukan dengan baik akan menghasilkan pendapatan ekonomi yang baik juga untuk komunitas setempat (Fritgen, 1996).

Menurut Mill

(2000)

pariwisata dapat memberikan keuntungan bagi wisatawan maupun tuan rumah dan dapat menaikkan taraf hidup melalui keuntungan secara ekonomi yang dibawa ke kawasan tersebut. Penduduk setempat mempunyai peran yang sangat penting dalam upaya pengembangan obyek wisata, karena penduduk setempat terlibat langsung dalam aktifitas-aktifitas yang berkaitan dengan kepariwisataan di daerah tersebut, bertindak sebagai tuan rumah yang ramah, penyelanggara atraksi wisata dan budaya khusus, produsen cindera mata yang memiliki ke khasan dari obyek tersebut dan turut menjaga keamanan lingkungan sekitar sehingga membuat wisatawan yakin, tenang, aman selama mereka berada di obyek wisata tersebut. Akan tetapi apabila suatu obyek wisata tidak dikembangkan atau ditangani dengan baik atau tidak direncanakan dengan matang, dapat menyebabkan kerusakan baik secara lingkungan maupun dampak-dampak negatif terhadap ekonomi maupun sosial.

Menurut Hadinoto (1996) suatu tempat wisata apabila tidak direncanakan dengan baik maka akan menyebabkan kerusakan lingkungan fisik, barang-barang 
sejarah, dan menimbulkan ketidaksukaan penduduk sekitar terhadap wisatawan maupun obyek wisata tersebut dimana pada akhirnya menimbulkan kerugian bagi pengelola tempat wisata tersebut.

Berikut adalah dampakdampak positif dari pengembangan suatu obyek wisata,yaitu :

1. Dampak ekonomi

Dampak positif dampak ekonomi ini ada yang langsung dan ada juga yang tidak langsung. Dampak positif langsungnya adalah : membuka lapangan pekerjaan yang baru dengan kemampuan, skill dari masyarakat sekitar yang bisa dipergunakan dengan berjualan makanan, minuman dan lain lain sehingga masyarakat lokal bisa mendapatkan peningkatan taraf hidup yang layak.

2. Dampak lingkungan

$$
\text { Pengembangan sebuah }
$$
obyek wisata sarana dan prasarana tersebut harus dilaksanakan sebaik mungkin karena apabila suatu obyek wisata dapat membuat wisatawan untuk berkunjung dan betah untuk melakukan wisata disana maka akan menyedot banyak pengunjung yang akan berguna juga untuk peningkatan ekonomi baik untuk komunitas di sekitar obyek wisata tersebut maupun pemerintah daerah.
3. Dampak sosial budaya

Dampak sosial budaya yang mungkin terjadi adalah

(Oktaviyanti, 2013)

a. Efek demonstratif

Berupa perubahan sikap, nilai dan perilaku masyarakat sekitar lokasi pantai. Diharapkan hal-hal positif membawa mayarakat sekitar makin berubah menjadi positif

b. Efek perubahan nilai budaya Interaksi antara masyarakat sekitar dan wisatawan akan menimbulkan perubahan seperti tenggang rasa, budaya materialistik dan perubahan pola hubungan pria dan wanita.

c. Pembelajaran Budaya

Bertemunya dua pihak yaitu masyarakat dan wisatawan menungkinkan terjadinya saling belajar budaya masing-masing dan terjadi pertemuan budaya sehingga hal positif atau negatif bisa terjadi

\section{Metode Penelitian}

Penelitian ini menggunakan metode deskriptive kuantitatif dengan menyebarkan kuesioner kepada 100 pengunjung untuk mendapatkan data. Responden berusia minimal 17 tahun karena dianggap sudah dewasa untuk memberikan pendapat. Metode purposive sampling dilakukan agar mendapatkan data sesuai tujuan penelitian. 
Adapun matriks penelitian adalah sebagai berikut:

Tabel 1 Matriks Penelitan

\begin{tabular}{llrl}
\hline No & \multicolumn{1}{c}{ Tujuan } & \multicolumn{1}{c}{ Sumber data } & Analisis data \\
\hline 1 & $\begin{array}{l}\text { Identifikasi karakteristik pengunjung, } \\
\text { unit usaha, tenaga kerja dan } \\
\text { masyarakat }\end{array}$ & & $\begin{array}{l}\text { Kuantitatif } \\
\text { deskriptive }\end{array}$ \\
2 & Dampak ekonomi & Kuesioner & Deskriptive \\
3 & Dampak lingkungan & Kuesioner & Kualitatif \\
\hline
\end{tabular}

\section{Hasil Penelitian}

\section{a. Karakteristik responden}

Jumlah responden yang dipilih untuk wisatawan sebanyak 100 orang, berdasarkan rumus:

$$
\begin{aligned}
\mathrm{n}=\mathrm{N} / & \left(1+\mathrm{Ne}^{2}\right) \\
& =287.0850 /\left(1+287.0850(0.1)^{2}\right) \\
& =100 \text { responden. }
\end{aligned}
$$

\begin{tabular}{|c|c|c|c|}
\hline No & Karakteristik & Frekuensi & $\begin{array}{c}\text { Persentase } \\
(\%)\end{array}$ \\
\hline \multirow[t]{4}{*}{1} & Jenis kelamin & & \\
\hline & Laki-laki & 56 & 56 \\
\hline & Perempuan & 44 & 44 \\
\hline & Jumlah & 100 & 100 \\
\hline \multirow[t]{6}{*}{2} & Usia (tahun) & & \\
\hline & $17-26$ & 45 & 45 \\
\hline & $27-36$ & 35 & 35 \\
\hline & $37-46$ & 19 & 19 \\
\hline & $>47$ & 1 & 1 \\
\hline & Jumlah & 100 & 100 \\
\hline \multirow[t]{7}{*}{3} & Tingkat pendidikan & & \\
\hline & SD & 4 & 4 \\
\hline & SMP & 10 & 10 \\
\hline & SMA/SMK & 50 & 50 \\
\hline & Diploma & 17 & 17 \\
\hline & Sarjana & 19 & 19 \\
\hline & Jumlah & 100 & 100 \\
\hline \multirow[t]{7}{*}{4} & Jenis pekerjaan & & \\
\hline & Pelajar/mahasiswa & 34 & 34 \\
\hline & Karyawan swasta & 24 & 24 \\
\hline & Wiraswasta & 9 & 9 \\
\hline & PNS & 6 & 6 \\
\hline & Ibu Rumah Tangga & 25 & 25 \\
\hline & Lainnya & 2 & 2 \\
\hline
\end{tabular}

Sedangkan karakteristik responden dapat dilihat dari tabel berikut:

Tabel 2 Karakteristik responden wisatawan berdasarkan faktor demografi 


\begin{tabular}{llcc}
\hline \multicolumn{1}{c}{ Jumlah } & 100 & 100 \\
\hline $5 \quad$ Pendapatan & & \\
\hline & $<500.000$ & 10 & 10 \\
$500.000-1.000 .000$ & 49 & 49 \\
$1.000 .001-2.000 .000$ & 28 & 28 \\
$2.000 .001-4.000 .000$ & 9 & 9 \\
$>4.000 .000$ & 4 & 4 \\
\hline Jumlah & 100 & 100 \\
\hline
\end{tabular}

Berdasarkan tabel diatas Pelajar dan mahasiswa maka dapat diketahui usia dominan mendominasi pengunjung sebanyak pengunjung adalah 17-26 tahun $34 \%$ dan tingkat pendidikan SMA sebanyak $45 \%$, dan pendapatan terbanyak didominasi Rp 500.000mendominasi sebanyak $50 \%$ Rp $\quad 1.000 .000$ sebanyak $49 \%$.

dilihat dari tingkat pendidikan

Sedangkan karakteristik responden berdasarkan frekuensi kunjungan dan cara kedatangan ke pantai Suwuk adalah sebagai berikut:

Tabel 3 Karakteristik responden wisatawan dalam berwisata

\begin{tabular}{llcc}
\hline No & Karakteristik & Frekuensi & Persentase (\%) \\
\hline 1 & Frekuensi berkunjung per tahun & & \\
\hline & $<7$ kali & 52 & 52 \\
& $7-13$ kali & 32 & 32 \\
& $14-20$ kali & 10 & 10 \\
& $21-27$ kali & 4 & 4 \\
& $>27$ kali & 2 & 2 \\
\hline & Jumlah & 100 & 100,00 \\
\hline 2 & Cara kedatangan & & 3 \\
\hline \multirow{2}{*}{ Sendiri } & 3 & 97 \\
& Kelompok & 97 & 100,00 \\
\hline & Jumlah & 100 & 80 \\
\hline 3 & Jumlah kelompok & & 16 \\
\hline & $<5$ orang & 80 & 4 \\
\hline & 5-10 orang & 16 & 100,00 \\
\hline & $>10$ orang & 4 & 13 \\
\hline & & 100 & 87 \\
\hline 4 & Jenis kendaraan & 13 & 100,00 \\
\hline & Mobil pribadi & 87 & \\
& Motor pribadi & 100 & \\
\hline & Jumlah & & \\
\hline
\end{tabular}

Sumber: Data Primer Diolah, 2019

Berdasarkan tabel diatas dapat dilihat berdasarkan cara kedatangan, responden yang berkunjung ke objek wisata Suwuk didominasi oleh responden wisatawan yang datang secara 
berkelompok, dengan proporsi terbesar 1-5 orang (80\%). Sehingga berdasarkan hal tersebut, menandakan bahwa tempat wisata ini cocok untuk dijadikan sebagai tempat berkumpul dan berwisata dengan kelompok

Tabel 4 daerah Daerah Asal

\begin{tabular}{lcc}
\hline Daerah asal & Frekuensi & Persentase (\%) \\
\hline Kebumen & 87 & 87 \\
Cilacap & 5 & 5 \\
Purworejo & 6 & 6 \\
Jogjakarta & 2 & 2 \\
\hline Jumlah & 100 & 100,00 \\
\hline
\end{tabular}

Sumber: Data Primer Diolah, 2019

Berdasarkan tabel diatas maka pengunjung lokal sebayak $87 \%$ mendominasi daerah asal selebihnya dari tetangga kabupaten yaitu Cilacap (5\%), Purworejo (6\%) dan Jogjakarta $(2 \%)$

b. Karakteristik Responden Pemilik Unit Usaha

Berdasarkan hasil wawancara, pemilik unit usaha yang ada di objek wisata pantai Suwuk (asongan, warung, kolam renang, penginapan, kuda dan motor, perahu) sebagian besar merupakan penduduk asli atau yang telah menetap di sekitar lokasi wisata sebanyak 30. Hal ini menunjukkan bahwa objek wisata pantai Suwuk memiliki peranan penting bagi perekonomian masyarakat sekitar objek wisata. Karakteristik responden pemilik unit usaha objek wisata Pantai Suwuk dapat dilihat pada tabel berikut.

Tabel 5 karakteristik responden pemilik unit usaha

\begin{tabular}{llcc}
\hline No & Karakteristik & Frekuensi & Persentase $(\%)$ \\
\hline 1 & Jenis kelamin & & \\
\hline & Laki-laki & 12 & 0,4 \\
& Perempuan & 18 & 0,6 \\
\hline & Jumlah & 30 & 100,0 \\
& & & \\
\hline 2 & Usia (tahun) & & 0,33 \\
& 30-40 & 10 & 0,37 \\
& $41-50$ & 11 & 0,27 \\
& 51-60 & 8 & 0,033 \\
& $>61$ & 1 & 100,0 \\
& Jumlah & 30 & 0 \\
& & & 0,033 \\
3 & Pendidikan & & 0,033 \\
& Tidak sekolah & 1 & 0,20 \\
Tidak tamat SD & 1 & 0,50 \\
SD & 6 & 0,24 \\
SMP & 15 & \\
& SMA/SMK & 7 & \\
\hline
\end{tabular}




\begin{tabular}{ccc}
\hline Jumlah & 30 & 100,0 \\
& & 0 \\
\hline
\end{tabular}

Sumber: Data Primer Diolah, 2019

\section{Dampak Lingkungan}

Analisis deskriptif dilakukan untuk mengetahui dampak lingkungan dari adanya kegiatan wisata di objek wisata Pantai Suwuk berdasarkan data primer yang diperoleh dari hasil wawancara kepada responden. Pernyataan responden dihubungkan dengan indikator skala dari buruk, sedang, hingga baik. Jumlah responden sebanyak 160 orang, terdiri dari 100 orang responden wisatawan, 30 orang responden unit usaha, dan 30 orang responden tenaga kerja.

\section{a. Persepsi kebersihan}

Kebersihan merupakan kategori yang penting dalam suatu keadaan lingkungan. Indikator kebersihan lingkungan di sepanjang pantai dibagi menjadi indikator tumpukan sampah, ketersediaan tempat sampah, dan kemudahan membuang sampah

\section{Tabel 7 Persepsi Kebersihan}

\begin{tabular}{|c|c|c|c|c|c|}
\hline \multirow[b]{2}{*}{ Indikator } & \multirow[b]{2}{*}{ Responden } & \multicolumn{3}{|c|}{ Persepsi } & \multirow{2}{*}{ Total } \\
\hline & & Baik & Sedang & Buruk & \\
\hline \multirow[t]{3}{*}{ Tumpukan sampah } & Wisatawan & 18 & 30 & 52 & 100 \\
\hline & Tenaga kerja & 4 & 18 & 8 & 30 \\
\hline & Unit usaha & 6 & 6 & 18 & 30 \\
\hline \multirow[t]{3}{*}{ Ketersediaan tempat sampah } & Wisatawan & 11 & 55 & 34 & 100 \\
\hline & Tenaga kerja & 2 & 20 & 8 & 30 \\
\hline & Unit usaha & 6 & 12 & 12 & 30 \\
\hline \multirow[t]{3}{*}{ Kemudahan membuang sampah } & Wisatawan & 21 & 66 & 13 & 100 \\
\hline & Tenaga kerja & 2 & 16 & 12 & 30 \\
\hline & Unit usaha & 12 & 6 & 12 & 30 \\
\hline
\end{tabular}

Sumber: Data Primer Diolah, 2019

Responden memiliki persepsi yang kurang baik mengenai kebersihan, sejumlah 52 responden wisatawan menyatakan tumpukan sampah buruk dan ketersediaan tempat sampah juga hanya dinilai sedang (34 responden), demikian juga dengan kemudahan membuang sampah haya dinilai sedang
(66 responden) sedangkan 13 responden menyatakan buruk ,Tenaga kerja dan unit usaha juga memiliki persepsi yang kurang baik mengenai fasilitas persampahan. 
Persepsi Responden tentang Kondisi

\section{Perairan Laut}

Kategori lain untuk dampak lingkungan adalah kondisi perairan laut yang ada di objek wisata Pantai Suwuk. Sebagai tempat wisata yang berbasiskan ekosistem pantai tentu harus memerhatikan kondisi perairan lautnya. Indikator kondisi perairan laut dibagi menjadi kejernihan perairan dan sampah di perairan

Tabel 7 Persepsi Kondisi Perairan

\begin{tabular}{|l|l|c|c|c|c|}
\hline \multirow{3}{*}{ Indikator } & \multirow{3}{*}{ Responden } & \multicolumn{3}{c|}{ Persepsi } & \\
\cline { 3 - 6 } & & Baik & Sedang & Buruk & \multirow{2}{*}{ Total } \\
\hline Kejernihan perairan & Wisatawan & 51 & 46 & 3 & 100 \\
\cline { 2 - 6 } & Tenaga kerja & 12 & 2 & 1 & 15 \\
\cline { 2 - 6 } & Unit usaha & 4 & 1 & 0 & 5 \\
\hline Sampah di perairan & Wisatawan & 56 & 41 & 3 & 100 \\
\cline { 2 - 6 } & Tenaga kerja & 13 & 1 & 1 & 15 \\
\cline { 2 - 6 } & Unit usaha & 4 & 1 & 0 & 5 \\
\hline
\end{tabular}

Sumber: Data Primer Diolah, 2019

Berdasarkan tabel diatas maka sebagian besar responden menyatakan kondisi perairan di pantai Suwuk baik (51\%) demikian juga dengan sampah sebagian besar responden menilai baik (56\%)

\section{Persepsi Responden tentang}

\section{Kondisi Udara}

Kondisi udara merupakan salah satu kategori penting dalam dampak lingkungan. Udara di suatu lokasi wisata seringkali tercemar oleh banyaknya sampah, asap kendaraan wisatawan, serta kurangnya pepohonan di dalam lokasi wisata. Responden wisatawan menyatakan persepsi baik sebanyak 95\% dan persepsi sedang 5\%. Tenaga kerja menyatakan $100 \%$ baik demikian juga dengan unit usaha

Persepsi Responden tentang

\section{Keindahan Alam}

Salah satu daya tarik objek wisata untuk menarik wisatawan adalah keindahan alamnya. Selain itu keindahan alam juga sebagai indikator kualitas lingkungan suatu objek wisata. Sebanyak $86 \%$ responden wisatawan menyatakan baik dan 14\% menyataan sedang. Sedangkan tenaga kerja memiliki persepsi baik untuk keindahan alam sebanyak 96\%, sebanyak $4 \%$ menyatakan sedang

\section{E. Simpulan}


Berdasarkan hasil pembahasan, maka dapat disimpulkan beberapa hal: Faktor-faktor yang berpengaruh dalam fungsi permintaan wisata di objek wisata Pantai Suwuk adalah biaya perjalanan dan jumlah tanggungan keluarga. Pariwisata di Pantai Suwuk dinilai memberikan kontribusi yang baik karena mampu menyerap tenaga kerja dan meningkatkan usaha di wilayah tersebut.

Dampak terhadap lingkungan dari adanya kegiatan wisata di objek wisata Pantai Suwuk menurut persepsi responden wisatawan, pemilik unit usaha, dan tenaga kerja dinilai kurang baik dalam hal pengelolaan sampah. Dampak lingkungan untuk kondisi perairan laut, kondisi udara, dan keindahan alam (Panorama), sebagian besar responden memberikan penilaian yang positif

Berdasarkan hasil simpulan tersebut maka sebaiknya pengelola benar benar memperhatikan kebersihan berkaitan dengan pengelolaan sampah. Sedangkan untuk kondisi panorama yang sudah dinilai baik maka sudah menjadi tanggung jawab pengelola untuk mempertahankan kondisi perairan agar tidak tercemar serta penataan taman mengingat pantai selatan rentan oleh kerusakan alam akibat tingginya ombak

\section{Daftar Pustaka}

Gee, C. Y., Mackens J. C., \& Choy, D. J. (1989). The Travel Industry. New York: Van Nostrand Reinhold.

Hadinoto, Kusudianto. (1996). Perencanaan Pengembangan Destinasi Pariwisata. Jakarta: UI Press.

Mill, Robert Christie. (2000). Tourist The International Business. Jakarta: PT Raja Grafindo Persada, Jakarta

Oktaviyanti, Sri Safitri (2013). Dampak sosial budaya interaksi wisatawan dengan masyarakat lokal di Kawasan Sosrowijayan. Jurnal Nasional Pariwisata.Vol 5 No 3 hal 201-208 